\title{
EVALUATION OF CYTOTOXICITY AND APOPTOTIC POTENTIAL OF OPHIORRHIZA PECTINATA ARN. - A POTENT ANTICANCER AGENT
}

\author{
PREETHA MOL SN*, JOHN E THOPPIL
}

Department of Botany, Cell and Molecular Biology Division, University of Calicut, Kerala, India. *Email: preethamolsn92@gmail.com

Received: 17 March 2019, Revised and Accepted: 15 June 2019

ABSTRACT

Objective: Ophiorrhiza pectinata Arn., a notable species belonging to the family Rubiaceae, is reported to be used in traditional and conventional medicines. The present study was aimed at the evaluation of the cytotoxic and apoptotic effects of the aqueous extract of 0 . pectinata.

Methods: Cytotoxic potential of the plant extract was analyzed using Allium cepa assay and the apoptotic effect of the plant extract was analyzed using Evan's blue staining technique.

Results: The extract was found to be cytotoxic at all tested concentrations, inducing several clastogenic and non-clastogenic aberrations at all the stages of mitosis. The clastogenic aberrations observed include chromosome coagulation, stickiness, chromosome bridges and fragments, nuclear lesions, and giant cells. Among non-clastogenic aberrations seen, the prominent ones were polyploidy, C-metaphase, stathmo-anaphase, ball metaphase, vagrants, tropokinesis, etc. The mitotic index was found to be decreasing with increase in concentration, whereas the abnormality percentage increased with an increase in the concentration of the plant extract. The in situ visualization of cell death by the Evan's blue staining method gave a positive relation between the concentration of the extract and its apoptotic activity.

Conclusion: As cytotoxicity and apoptosis are bioactivities related to anticancer potential, the study proves that the plant is of high therapeutic efficacy and requires more exploration toward its usefulness in drug discovery.

Keywords: Ophiorrhiza, Cytotoxicity, Apoptosis, Anticancer, Therapeutic.

(C) 2019 The Authors. Published by Innovare Academic Sciences Pvt Ltd. This is an open access article under the CC BY license (http://creativecommons. org/licenses/by/4. 0/) DOI: http://dx.doi.org/10.22159/ajpcr.2019.v12i8.34176

\section{INTRODUCTION}

Plants are the major source of natural medicines. Several products derived from plants have been used for thousands of years in traditional medicines to treat various human illnesses [1]. According to the reports of the World Health Organization, about $80 \%$ of the population in developing countries relies on traditional medicines for their healthcare needs [2]. Although thousands of plants are well known for their ethnomedicinal properties, only $1-10 \%$ of these are scientifically studied for their potential medicinal use [3]. As the medicinal properties of all plants rely on their bioactive chemical constituents, large numbers of plants are constantly screened for the manufacture of new drugs with fewer side effects [4].

Recent years have witnessed the emergence of several dreadful diseases that wiped out thousands of lives. Cancer has become one such devastating disease, affecting millions of people worldwide. It accounts for more than $13 \%$ of all human deaths [5]. Although modern technology has developed synthetic drugs and therapies for the treatment, cancer still affects the quality of life. An alternative to this is the use of herbal-based drugs, and thus, medicinal plants become the principle source of anticancer agents [6].

Plants that are used in traditional and folklore medicines to treat and prevent diseases like cancer might possess compounds that could play a major role in the development of useful anticancer agents [7]. Agents with antiproliferative and apoptosis-inducing capacity are currently used in cancer treatment [8], so the assessment of cytotoxic and apoptotic efficacy of medicinal plants is important to validate their use as anticancer agents.

The present study was designed to assess the cytotoxic and apoptotic efficacy of the plant Ophiorrhiza pectinata Arn., belonging to the family
Rubiaceae. Ophiorrhiza L. is a notably species-rich genus consisting of 321 species, five varieties, and one subspecies [9] and found in wet tropical forests of South-East Asia, extending to Australia, New Guinea, and Pacific Islands. Ophiorrhiza species are small herbaceous or shrubby plants that possess many medicinal properties. They have been used in traditional and folk medicine as snakebite antitussive, and analgesic and for the treatment of ulcers, leprosy, gastropathy, and amenorrhea [10]. The presence of camptothecin (in some species), a cytotoxic alkaloid, which is the only natural occurring topoisomerase-I inhibitor [11,12] gives great importance to the genus in cancer research. The present study is the first attempt to analyze the cytotoxic and apoptotic efficacy of the plant, O. pectinata on Allium cepa root cells. The study tries to evaluate the potential of the plant to be used as an anticancer agent.

\section{METHODS}

\section{Collection of plant material}

Fresh plant materials (whole plant) of 0 . pectinata were collected from Kulamavu, Idukki district, Kerala, India. The geographical coordinates of the place correspond to $9^{\circ} 41^{\prime} 53.21^{\prime \prime} \mathrm{N}$ and $76^{\circ} 55^{\prime}$ $38.74^{\prime \prime} \mathrm{E}$ at an altitude of $800 \mathrm{~m}$ above sea level. The taxonomic authentication of the collected plant materials was done by Dr. M. Sabu, Professor, Angiosperm Taxonomy Division, Department of Botany, University of Calicut, Kerala, India. The voucher specimen (CALI no: 143972) was deposited in the Calicut University Herbarium.

Test material and chemicals used

A. cepa (Onion) bulbs, $2 \mathrm{n}=16$, free from pesticides and other forms of growth inhibitors were procured from agricultural vendors and used as the test material. Evan's blue stain and N, N-dimethylformamide were purchased from HiMedia Chemical Laboratory (Mumbai, India). 
Preparation of plant extract

The collected plants were thoroughly washed to remove all the dirt and dust and were shade-dried. After drying, they were powdered in a blender and stored in moisture free sealed container. For the preparation of the plant extract, $1 \mathrm{~g}$ of the powder is dissolved in $100 \mathrm{ml}$ of distilled water using chilled mortar and pestle. This solution of $1 \%$ concentration served as the stock solution. From the stock solution, extracts of various concentrations $(0.1 \%, 0.05 \%, 0.01 \%$, and $0.005 \%)$ were prepared.

\section{Evaluation of cytotoxicity}

A. серa root tip assay was done for analyzing the cytotoxic potential of the plant extract. For this, fresh and healthy, uniformly sized onion bulbs were selected and the outer dry scales were removed without destroying the root primordia and grown on sterilized, moist sand. On germination, onion bulbs with roots of length
1-2 $\mathrm{cm}$ were collected at the time of peak mitotic activity (9-10 am), standardized by repeated trial and error, and washed in distilled water. After thorough washing, the bulbs were suspended in different concentrations of the plant extract for $24 \mathrm{~h}$ treatment. Care was taken that only roots of the bulbs get immersed in extracts. Distilled water and hydrogen peroxide $(0.1 \%)$ were used as the negative control (NC) and positive control (PC), respectively. After treatment, roots were cut from the bulbs and washed in distilled water, followed by fixation in modified Carnoy's fluid (1 acetic acid:2 ethanol) for $1 \mathrm{~h}$. Mitotic squash preparation was done following the methodology of Sharma and Sharma (1990) with slight modifications [13]. The fixed root tips were washed with distilled water and hydrolyzed in $1 \mathrm{~N}$ hydrochloric acid for $5 \mathrm{~min}$. The roots were then washed and stained with $2 \%$ acetocarmine for $3 \mathrm{~h}$. After destaining using $45 \%$ acetic acid, the roots were squashed and mounted in $45 \%$ acetic acid on clean glass slides. The mounted slides were observed under

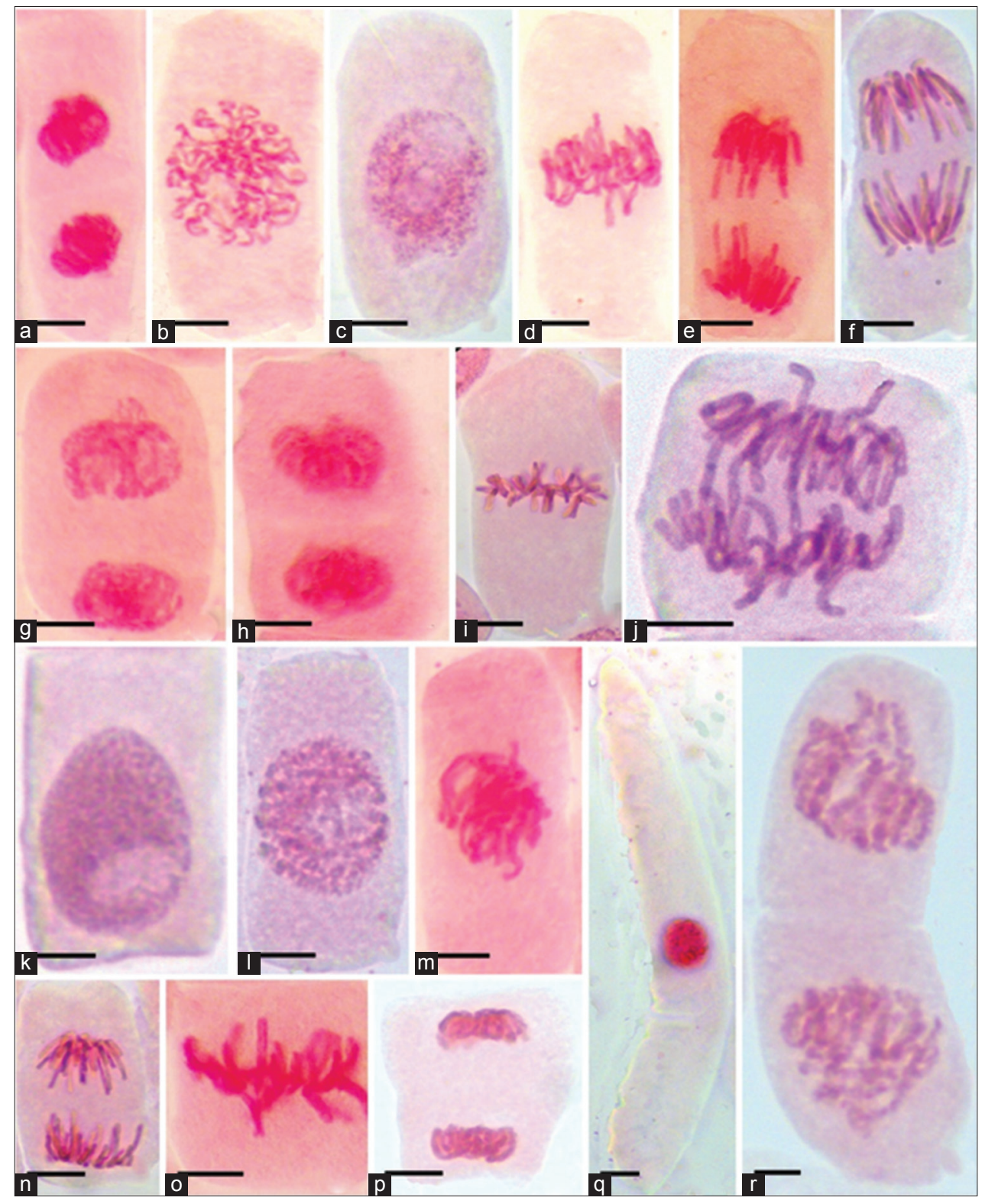

Fig. 1: Clastogenic aberrations induced by aqueous extract of Ophiorrhiza pectinata on Allium cepa root tip cells. (a) Coagulated anaphase, (b) ring chromosomes in early ball metaphase, (c) pulverized early prophase, (d) sticky metaphase, (e) sticky anaphase, (f) fragments at anaphase, (g) sticky late telophase, (h) pulverized chromatin at cytokinesis, (i) hypercondensed chromosomes, (j) chromosome bridges at C-anaphase in a hyperploid cell, (k) single nuclear lesion at early prophase, (l) pulverized prophase, (m) coagulated metaphase, (n) chromosome erosion at anaphase, (o) sticky hypercondensed chromosomes at metaphase, (p) telophase showing chromosome erosion, (q) giant cell showing cell shrinkage, (r) chromatin gaps and erosion at late cytokinesis. Bar $=10 \mu \mathrm{m}$ 
$40 \times$ objective of light microscope (Leica DM 2000 LED, Germany) and photomicrographs were taken. Six different fields were randomly selected to calculate the number of mitotic cells, aberrant cells, and total number of cells. Mitotic index (\%) and abnormality percentage $(\%)$ were calculated using the formulae,

Mitotic index $(\%)=\frac{\text { Number of diving cells }}{\text { Totalnumber of cells }} \times 100$

Abnormality percentage $(\%)=\frac{\text { Number of aberrant cells }}{\text { Totalnumber of cells }} \times 100$

\section{Evaluation of apoptosis}

In situ visualization of cell death using Evan's blue staining method [14] with slight modifications was followed for assessing the apoptotic effect of the plant extract. Onion bulbs with roots of length 4-5 cm were selected and washed with distilled water. The bulbs were then treated with different concentrations of the plant extract for $24 \mathrm{~h}$. The bulbs are so placed that only roots get immersed in the extract

Roots treated in distilled water were taken as the NC and those treated in hydrogen peroxide $(0.1 \%)$ were taken as the PC. The treated roots were washed and kept in $0.25 \%$ (w/v) of Evan's blue aqueous solution for $15 \mathrm{~min}$. After thorough washing in distilled water, the
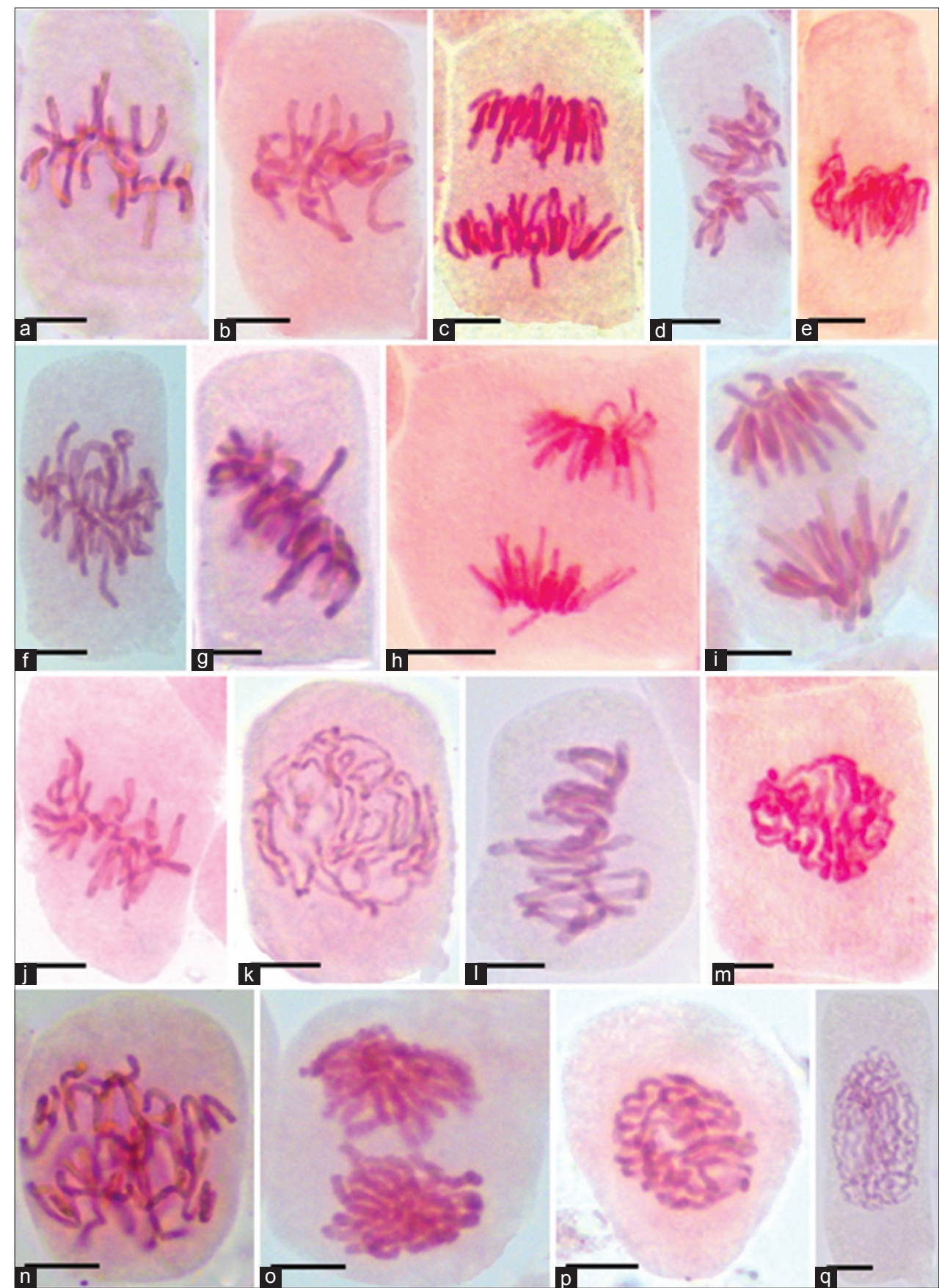

m

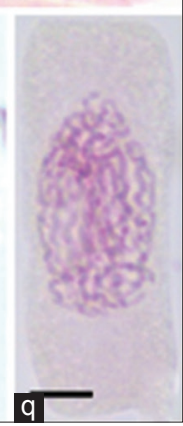

Fig. 2: Non-clastogenic aberrations induced by aqueous extract of Ophiorrhiza pectinata on Allium cepa root tip cells. (a) Tropokinesis, (b) vagrant metaphase in a hypoploid cell, (c) vagrants at anaphase, (d) diagonal partial C-metaphase, (e) chromosome clumping at metaphase, (f) disturbed metaphase, (g) diagonal metaphase showing vagrants, (h) shift in MTOC at anaphase, (i) diagonal partial C-anaphase, (j) partial C-metaphase, (k) scattered ball metaphase, (l) pole-to-pole metaphase, (m) chained ball metaphase, (n) stathmoanaphase, (o) stellate anaphase, (p) ball metaphase, (q) early ball metaphase. Bar $=10 \mu \mathrm{m}$ 
roots with dead cells, that have stained blue, were photographed. For quantitative estimation of the cell death, five stained roots of equal length were excised from each onion bulb and immersed in $3 \mathrm{ml}$ of $\mathrm{N}$, $\mathrm{N}$-dimethylformamide for $1 \mathrm{~h}$. The absorbance of the released Evan's blue stain was spectrophotometrically measured with the help of UVvisible spectrophotometer (Elico, India) at a wavelength of $600 \mathrm{~nm}$ and the values were recorded. All the tests were done in triplicates.

\section{Statistical analysis}

All the statistical analyses were done using the SPSS Version 20 software program. The data obtained were subjected to one-way analysis of variance and Duncan's multiple range tests to validate the results. The results were expressed as mean \pm standard error and those with ${ }^{*} \mathrm{p}<0.05$ were treated as statistically significant.

\section{RESULTS}

\section{Evaluation of cytotoxicity}

The plant extract of $O$. pectinata was found to be cytotoxic at all the tested concentrations, inducing several clastogenic and non-clastogenic aberrations in A. cepa root tip cells in all the mitotic stages. The major clastogenic aberrations observed were coagulated anaphase (Fig. 1a), sticky metaphase (Fig. 1d), sticky anaphase (Fig. 1e), hypercondensed chromosomes (Fig. 1i), chromosome bridges at C-anaphase in a hyperploid cell (Fig. 1j), pulverized prophase (Fig. 11), chromosome erosion at anaphase (Fig. 1n), giant cell showing cell shrinkage (Fig. 1q), etc. The major non-clastogenic aberrations induced were tropokinesis (Fig. 2a), vagrants at anaphase (Fig. 2c), chromosome clumping at metaphase (Fig. 2e), disturbed metaphase (Fig. 2f), shift in microtubule organizing center (MTOC) at anaphase (Fig. 2h), partial C-metaphase (Fig. 2j), scattered ball metaphase (Fig. 2k), pole-to-pole metaphase (Fig. 2l), chained ball metaphase (Fig. 2m), stathmo-anaphase (Fig. 2n), stellate anaphase (Fig. 2o), ball metaphase (Fig. 2p), etc.

Mitotic index was found to be decreasing with an increase in the concentration of the plant extract when compared with control. A gradual reduction of mitotic index was observed from lower to higher concentrations of the plant extract. The highest concentration of the plant extract $(0.1 \%)$ exhibited a mitotic index percentage of $28.56 \pm 2.93$ and the lowest concentration $(0.005 \%)$ showed a higher mitotic index percent of $73.68 \pm 6.85$. The abnormality percentage increased from $29.95 \pm 4.44$ at $0.005 \%$ to $85.86 \pm 3.55$ at $0.1 \%$ of the aqueous extract. Mitotic index thus obtained indicated a dose-dependent reduction in the number of normal dividing cells and a dose-dependent increase was found in the number of aberrant cells, both signifying the cytotoxic potential of the plant. The mitotic index and abnormality percentage induced by various concentrations of the extract are given in Table 1

\section{Evaluation of apoptosis}

Evan's blue staining method revealed the apoptotic effect of the plant, o. pectinata. Fig. 3 shows the gradual increase in the intensity of the stain uptake by $A$. cepa roots treated with lower to higher concentrations of the plant extract. As the intensity of the stain absorbed by root cells is related to cell death, this indicated the increasing apoptotic effect of the plant extract.

Quantitative estimation of the cell death by spectrophotometric method indicated a dose-dependent increase in apoptosis from lower to higher concentrations of the plant extract. The absorbance of Evan's blue stain for various concentrations of the plant extract on A. cepa root tip cells is summarized in Table 2.

\section{DISCUSSION}

Cytotoxicity is an important bioactivity of medicinal plants that can be related to their anticancer potential [15]. Various secondary metabolites present in the plant produce cytotoxic effect by disturbing the normal cell cycle [16] and inducing different forms of chromosomal aberrations. The extract of 0 . pectinata induced aberrations at all mitotic stages and this could be the synchronized effect of the chemical
Table 1: Mitotic index and abnormality percentage induced by various concentrations of the aqueous extract of Ophiorrhiza pectinata on Allium cepa root tip cells treated for $24 \mathrm{~h}$

\begin{tabular}{lll}
\hline $\begin{array}{l}\text { Concentration of the } \\
\text { plant extract (\%) }\end{array}$ & Mitotic index \% \pm SE & $\begin{array}{l}\text { Abnormality } \\
\text { percentage } \pm \text { SE }\end{array}$ \\
\hline NC & $83.26 \pm 2.25^{\mathrm{c}}$ & $7.41 \pm 3.20^{\mathrm{a}}$ \\
PC & $27.50 \pm 1.12^{\mathrm{a}}$ & $86.71 \pm 2.01^{\mathrm{d}}$ \\
$0.005 \%$ & $73.68 \pm 6.85^{\mathrm{c}}$ & $29.95 \pm 4.44^{\mathrm{b}}$ \\
$0.01 \%$ & $49.80 \pm 6.85^{\mathrm{b}}$ & $67.01 \pm 3.62^{\mathrm{c}}$ \\
$0.05 \%$ & $33.85 \pm 4.59^{\mathrm{a}}$ & $83.33 \pm 3.50^{\mathrm{d}}$ \\
$0.1 \%$ & $28.56 \pm 2.93^{\mathrm{a}}$ & $85.86 \pm 3.55^{\mathrm{d}}$ \\
\hline
\end{tabular}

Means in a column with similar superscripts are not significantly different at ${ }^{*} \mathrm{p}<0.05$ as determined by Duncan's multiple range tests. NC: Negative control, PC: Positive control, SE: Standard error

Table 2: Absorbance of Evan's blue stain at various concentrations of the aqueous extract of Ophiorrhiza pectinata on Allium cepa root tip cells treated for $24 \mathrm{~h}$

\begin{tabular}{ll}
\hline Concentration of the plant extract (\%) & Absorbance at $\mathbf{6 0 0} \mathbf{~ n m}$ \\
\hline NC & $0.02 \pm 0.003^{\mathrm{a}}$ \\
PC & $0.44 \pm 0.032^{\mathrm{d}}$ \\
$0.005 \%$ & $0.06 \pm 0.005^{\mathrm{a}, \mathrm{b}}$ \\
$0.01 \%$ & $0.08 \pm 0.001^{\mathrm{b}}$ \\
$0.05 \%$ & $0.14 \pm 0.0009^{\mathrm{c}}$ \\
$0.1 \%$ & $0.16 \pm 0.005^{\mathrm{c}}$ \\
\hline
\end{tabular}

Means in a column with similar superscripts are not significantly different at ${ }^{*} \mathrm{p}<0.05$ as determined by Duncan's multiple range tests. NC: Negative control, PC: Positive control

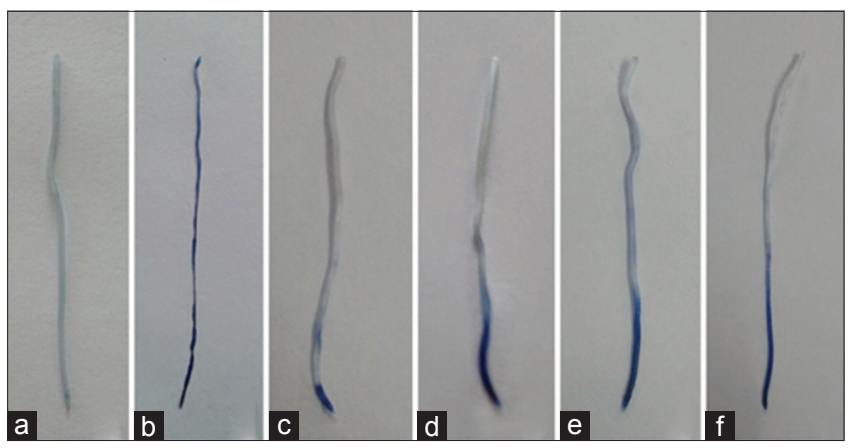

Fig. 3: Apoptosis induced by different concentrations of plant extract of Ophiorrhiza pectinata on Allium cepa root tip cells. (a) Negative control, (b) positive control, (c) $0.005 \%$, (d) $0.01 \%$, (e) $0.05 \%$, (f) $0.1 \%$

constituents in the extract that blocks DNA synthesis or inhibits spindle formation.

Nuclear lesions observed could be the inhibitory effect of the extract on DNA biosynthesis [17]. Pulverization was another abnormality observed. This might be due to the premature condensation of the chromosomes [18]. Stickiness might occur from improper folding of the chromosome fibers [19] and chromosomal bridges and fragments arise due to the breaks in chromosomes and chromatids [20]. Alteration in the viscosity due to the depolymerization of the DNA might be the reason for chromosome coagulation. Hypercondensed chromosomes were also one of the prominent abnormalities seen. Sosnikhina et al. (2003) described the aberration as irregular compaction and stickiness of chromosomes [21]. Formation of giant cell could be attributed to the disruption in "S" phase and thereby cell expansion leading to enlarged cell size.

Among the non-clastogenic aberrations observed, tropokinesis might have occurred due to abnormal orientation of spindle fibers. The 
same defect of the spindle fibers would be the reason for diagonal or disorientation of chromosomes and shift in MTOC [22]. Hyperploid cells would have emerged due to multipolar mitosis [23]. Pole-topole orientation of chromosomes at metaphase was also observed in cells, which would have resulted due to irregular pathways of spindle assembly and altered spindle activity [24]. Ball-shaped arrangement of chromosomes due to the localized action of the spindle apparatus at the center that makes the chromosomal centromeres to be at the equator and arms to radiate at different directions was also observed in different mitotic stages [25]. Stathmo-anaphase, where the chromosomes remain connected by partial overlapping of the arms, was also observed in cells. Stellate arrangement of chromosomes might have occurred as a result of the spindle disturbances or due to the clumping of daughter chromosomes to a star-like form [26].

Mitotic index is a reliable parameter to measure cytotoxicity within living organisms [27]. Reduced rate of mitotic index is an index of cytotoxic potential of the plant extract. A dose-dependent decrease of mitotic index with increasing concentration of the extract was observed. Similarly, a dose-dependent increase of abnormality percentage was also observed. According to Anjana and Thoppil (2013), reduced mitotic index indicates the presence of cytotoxic substances in the extract that inhibits mitotic activities and produces aberrant cells by its genotoxic effects on the treated root tip cells [7]. Sudhakar et al. (2001) explained that the reduced mitotic activities might be due to the blockage in DNA synthesis or G2 phase in cell cycle that inhibits the cells to enter mitotic phase [28].

A. cepa root tip cells treated with the plant extract might suffer from genotoxic stress and such cells either complete nuclear division or undergo apoptosis [29]. Apoptosis is a biological response of the cells with DNA damaged that forms an excellent marker to screen compounds for developing potent anticancer agents [30]. The main aim of using anticancer agents is the induction of apoptosis or cell death-related signals that disturb cancer cell proliferation [4]. Cell death that marks cytotoxicity could be revealed by Evan's blue staining method [31]. The stain deeply penetrates non-viable cells. Thus, the intensity of stain uptake by treated and control roots of $A$. cepa provides indirect evidence of cell death as dead cells are deeply stained than viable cells [32]. The dose-dependent increase in the uptake of the stain by the root tip cells indicated higher rate of cell death at higher concentrations of the extract signifying the apoptotic potential of the plant. Spectrophotometric determination of apoptosis also signified the same.

\section{CONCLUSION}

Evaluation of the cytotoxicity of 0 . pectinata mediated by the assessment of apoptotic efficacy revealed that the plant may be formulated as a potent therapeutic agent. The various chromosomal aberrations induced by the plant extract on the root tip cells of $A$. cepa indicate its antimitotic activity, thus preventing cell division. A dose-dependent reduction of mitotic index values and a dose-dependent increase of abnormality percentage marked the cytotoxic potential of the plant. In situ visualization of cell death by Evan's blue staining suggested an indirect evidence of apoptosis or programmed cell death, which is an important property for anticancer agents.

A. cepa assays are extensively used to evaluate the cytotoxic, antimitotic, genotoxic, and apoptotic potential of medicinal plants and further works are required to confirm the specificity of the plant for therapeutic use. However, the results suggest that the plant is an effective source for anticancer studies.

\section{ACKNOWLEDGMENT}

The authors are grateful to the Forest Department of Kerala for providing the permission for plant collection. The first author acknowledges the Government of Kerala for providing the financial support for conducting the study.

\section{AUTHORS' CONTRIBUTIONS}

The first author designed the work, performed the laboratory experiments, collected the data, and prepared the manuscript.

The second author reviewed the manuscript and made proper corrections to improve its quality.

\section{CONFLICTS OF INTEREST}

Both the authors declare that there are no conflicts of interest with respect to the publication of this research article.

\section{REFERENCES}

1. Ramana KV, Singhal SS, Reddy AB. Therapeutic potential of natural pharmacological agents in the treatment of human diseases. Biomed Res Int 2014;2014:573452.

2. Ruwali P, Adhikari M, Sharma S. Phytochemical and antioxidant properties of various extracts of Michelia champaca leaves. Int J Pharm Pharm Sci 2019;11:56-61.

3. Verpoorte R. Pharmacognosy in the new millennium: Leadfinding and biotechnology. J Pharm Pharmacol 2000;52:253-62.

4. Prajitha V, Thoppil JE. Cytotoxic and apoptotic activities of extract of Amaranthus spinosus L. In Allium cepa and human erythrocytes. Cytotechnology 2017;69:123-33.

5. Manikandan S, Ganesapandian S, Singh M, Kumaraguru AK. Antitumour activity of bromopyrrole alkaloids against human breast tumour (MCF-7) through apoptosis induction. Int J Pharm Pharm Sci 2019;11:94-100.

6. Newman DJ, Cragg GM, Holbeck S, Sausville EA. Natural products and derivatives as leads to cell cycle pathway targets in cancer chemotherapy. Curr Cancer Drug Targets 2002;2:279-308

7. Anjana S, Thoppil JE. Analysis of cytotoxic potential of the aqueous leaf extracts of Pogostemon auricularius (L.) Hassk. using Allium cepa root tip assay. Int J Res Dev Pharm Life Sci 2013;2:562-6.

8. Willett WC, Trichopoulos D. Nutrition and cancer: A summary of the evidence. Cancer Causes Control 1996;7:178-80

9. Hareesh VS, Sabu M. The genus Ophiorrhiza (Rubiaceae) in Andaman and Nicobar Islands, India with a new species. Phytotaxa 2018;383:259-72.

10. Rajan R, Varghese SC, Kurup R, Gopalakrishnan R, Venkataraman R, Satheeshkumar K, et al. Search for camptothecin-yielding Ophiorrhiza species from southern Western Ghats in India: A HPTLC-densitometry study. Ind Crops Prod 2013;43:472-6.

11. Martin KP, Beegum AS, Zhang CL, SlaterA, Madhusoodanan PV. In vitro propagation of Ophiorrhiza prostrata through somatic embryogenesis. Biol Plant 2007;51:769-72.

12. Yamazaki Y, Urano A, Sudo H, Kitajima M, Takayama H, Yamazaki M, et al. Metabolite profiling of alkaloids and strictosidine synthase activity in camptothecin producing plants. Phytochemistry 2003;62:461-70.

13. Sharma AK, Sharma A. Chromosome Techniques: Theory and Practice. New Delhi: Aditya Books; 1990.

14. Baker CJ, Mock NM. An improved method for monitoring cell death in cell suspension and leaf disc assays using evans blue. Plant Cell Tissue Organ Cult 1994;39:7-12.

15. Anjana S, Thoppil JE. Evaluation of cytotoxicity of the aqueous leaf extract of Pogostemon heyneanus Benth. (Java patchouli). BIOTROPIA South Asian J Trop Biol 2017;24:28-34.

16. Gali-Muhtasib H, Bakkar N. Modulating cell cycle: Current applications and prospects for future drug development. Curr Cancer Drug Targets 2002;2:309-36.

17. Majewska A, Wolska E, Śliwińska E, Furmanowa M, Urbańska N, Pietrosiuk A, et al. Antimitotic effect, G2/M accumulation, chromosomal and ultrastructure changes in meristematic cells of Allium cepa L. root tips treated with the extract from Rhodiola rosea roots. Caryologia 2003;56:337-51.

18. Knuutila S, Siimes M, Vuopio P. Chromosome pulverization in blood diseases. Hereditas 1981;95:15-24.

19. Hellgren L, Morré DJ. ATP-induced budding of nuclear envelope in vitro. Protoplasma 1992;167:238-42.

20. Fiskesjo G. Allium test for screening chemicals; evaluation of cytological parameters. Plants Environ Stud 1997;101:307-33.

21. Sosnikhina SP, Kirillova GA, Mikhailova EI, Tikholiz OA, Smirnov VG, Nemtsova NS. Abnormal condensation of meiotic chromosomes caused by the mei8 mutation in rye Secale cereale L. 
Russ J Genet 2003;39:288-94.

22. Selim AR, Hussein MM, Allam HZ, Farah AR. The effect of three synthetic organic insecticides (nuvacron, cyolan and kelthane/dimethoate) on the cytological features and morphological characters in cotton Gossypium barbadense 1. Bull Fac Agric Cairo Univ 1981;32:52-66.

23. Seoane AI, Güerci AM, Dulout FN. Mechanisms involved in the induction of aneuploidy: The significance of chromosome loss. Genet Mol Biol 2000;23:1077-82.

24. Waters JC, Salmon E. Pathways of spindle assembly. Curr Opin Cell Biol 1997;9:37-43.

25. Morgan DO. The Cell Cycle: Principles of Control. London: New Science Press; 2007

26. Raj AS, Rao VR. Cytological studies in Vicia faba L. treated with lathyrogens. Cytologia 1972;37:245-56

27. Smaka-Kincl V, Stegnar P, Lovka M, Toman MJ. The evaluation of waste, surface and ground water quality using the Allium test procedure. Mutat Res 1996;368:171-9.
28. Sudhakar R, Gowda KN, Venu G. Mitotic abnormalities induced by silk dyeing industry effluents in the cells of Allium cepa. Cytologia 2001;66:235-9.

29. Kirsch-Volders M, Elhajouji A, Cundari E, Van Hummelen P. The in vitro micronucleus test: A multi-endpoint assay to detect simultaneously mitotic delay, apoptosis, chromosome breakage, chromosome loss and non-disjunction. Mutat Res 1997;392:19-30.

30. Arulvasu C, Prabhu D, Manikandan R, Srinivasan P, Dinesh D, Babu G, et al. Induction of apoptosis by the aqueous and ethanolic leaf extract of Vitex negundo L. in MCF-7 human breast cancer cells. Int J Drug Discov 2010;2:1-7.

31. Panda KK, Achary VM, Krishnaveni R, Padhi BK, Sarangi SN, Sahu $\mathrm{SN}$, et al. In vitro biosynthesis and genotoxicity bioassay of silver nanoparticles using plants. Toxicol In Vitro 2011;25:1097-105.

32. Bhagyanathan NK, Thoppil JE. Pre-apoptotic activity of aqueous extracts of cynanchum sarcomedium meve and; liede on cells of Allium серa and human erythrocytes. Protoplasma 2016;253:1433-8. 